\title{
CIBERCULTURA E AS IDENTIDADES LÍQUIDAS: REFLEXÃO SOBRE A CULTURA NA ERA DAS NOVAS TECNOLOGIAS
}

\author{
Úrsula Nascimento de Sousa Cunha
}

\begin{abstract}
Uma coisa é certa: vivemos hoje em uma dessas épocas limítrofes na qual toda a antiga ordem das representações e dos saberes oscila para dar lugar a imaginários, modos de conhecimento e estilos de regulação social, ainda pouco estabilizados. Vemos um destes raros momentos em que, a partir de uma nova configuração técnica, quer dizer, de uma nova relação com o cosmo, um novo estilo de humanidade é inventado.
\end{abstract}

Pierre Lèvy, 1995

RESUMO: Este artigo - um recorte do meu projeto de pesquisa para o doutorado em Educação (UFPB), na linha Estudos Culturais da Educação - tem por objetivo refletir a respeito da concepção de cultura em uma época dominada pelas Tecnologias da Informação e Comunicação (TIC) e como essas ferramentas têm influenciado as manifestações culturais de grupos sociais e suas identidades, através de um processo de justaposição cultural, característica da cibercultura. Para isso, torna-se essencial refletir sobre algumas concepções de cultura, apesar de esse ser um conceito difuso e cambiante, tendo como épocas principais a modernidade e a pós-modernidade, que determinaram alguns tipos culturais, a exemplo da cultura de imprensa, de massas, midiática e digital, a partir do olhar dos Estudos Culturais. Dessa forma, na contemporaneidade, evidenciam-se os hibridismos culturais, os descentramentos da identidade e, ao mesmo tempo, a heterogeneidade da cibercultura, através das comunidades virtuais e da relação de troca entre produtor cultural e consumidor, que tende a romper a hierarquia entre alta e baixa cultura. Portanto, as novas tecnologias são suportes que relativizam o poder do autor de impor significados ou de oferecer uma narrativa contínua em relação às manifestações culturais vigentes.

PALAVRAS-CHAVE: Cibercultura. Cultura cibernética. Cultura digital. Identidades líquidas. Estudos Culturais.

ABSTRACT: This article - a snip of my research project for his doctorate in Education (UFPB), in line Cultural Studies Education - aims to reflect on the concept of culture in an era dominated by the Information Technology and Communication (ICT) and how these tools have influenced the cultural manifestations of social groups and their identities through a process of cultural apposition characteristic of cyber culture. For this, it is essential to reflect on some conceptions of culture, although this is a concept diffuse and changeable, having as main epochs modernity and post modernity, which led to some cultural types, such as culture media, mass , and digital media, from the look of Cultural Studies. Thus, in contemporary times, show up the cultural hybridism, overthrows of identity and, at the same time, the heterogeneity of cyber culture, through virtual communities and the relationship of cultural exchange between producer and consumer, it tends to break down the hierarchy between high and low culture. Therefore, new technologies are supports that relativize the power of the author to impose meanings or offer a continuous narrative in relation to current cultural manifestations.

KEYWORDS: Cyberculture. Cyber culture. Digital culture. Identities net. Cultural Studies. 


\section{CONSIDERAÇÕES INICIAIS}

A cibercultura, cultura cibernética ou cultura digital, caracteriza um conceito emergente da pós-modernidade, que nasce da perspectiva do impacto das novas tecnologias e da conexão em rede na sociedade. Essa cultura promove uma recombinação da ciência com as artes, utilizando-se da metalinguagem digital e da capacidade de remontar arquivos para exprimir a produção simbólica de um determinado grupo social, mas que atinge a todos que estão conectados à rede.

As metonímias oriundas dessas composições culturais deixam evidentes a polifonia do discurso e sua aceitação social, através da desconstrução de uma ideia totalizante em relação às suas manifestações, que, em alguns momentos do mundo moderno, representavam dicotomias quanto ao valor cultural dos produtos, o que constitui, por assim dizer, a negação da essência da visão pós-moderna. Dessa forma, na pós-modernidade, segundo Derrida (1996), firma-se um olhar cultural semelhante a uma série de textos em intersecção com outros textos, produzindo mais textos. Ou seja, a cultura contemporânea consiste em uma técnica de colagem/montagem, de bricolagens: representa a justaposição de elementos distintos e aparentemente incongruentes, o que também é uma forte característica do mundo digital e suas redes de comunicação.

Além disso, essas redes tecnológicas oferecem uma comunicação do tipo "muitos-a-muitos", uma transmissão múltipla, fator extremamente importante na pósmodernidade, tendo em vista que possibilita que várias pessoas se tornem produtoras e distribuidoras de seus próprios produtos culturais, o que pode revelar, muitas vezes, uma identidade líquida ${ }^{\mathbf{1}}$. Assim, as Tecnologias da Informação e Comunicação (TIC) permitem a minimização da autoridade do produtor cultural, pois criam a oportunidade da participação popular e valida sua autoria. Percebe-se que é possível relativizar, através da cibercultura, o poder do autor de impor significados ou de oferecer uma narrativa contínua e única, pois, conforme salienta Escosteguy $(2005$, p. 88),

A ideia defendida abarca uma visão ampla e complexa do processo de recepção dos produtos midiáticos onde são consideradas múltiplas

\footnotetext{
${ }^{1}$ A partir da metáfora de Bauman (2001) sobre a modernidade líquida, aproprio-me da adjetivação do autor para caracterizar a concepção de identidade pós-moderna, categoria a ser discutida com mais detalhes no decorrer deste artigo.
} 
relações sociais e culturais, portanto, trata-se de uma ruptura com concepções passivas da audiência, substituindo-as por uma abordagem mais dinâmica, onde se passa a pensar a relação existente entre o campo de emissão/produção e recepção/consumo.

Os Estudos Culturais (EC), nessa dinâmica, contribuem como campo de pesquisa e possibilitam se pensar o sentido da comunicação/interação a partir das novas tecnologias, considerando-as como um processo sociocultural, em que se destaca a ação de diversos sujeitos envolvidos na produção de sentido (ESCOSTEGUY, 2005). Além disso, outro ponto importante a se destacar em relação aos EC e às TIC é a possibilidade de uma "emancipação da identidade" (KLEIMAN e VIEIRA, 2006), ou seja: "a capacidade de os sujeitos desvincularem-se do local para se ligarem ao global" (Ibidem, p. 122), sem, contudo, perder a identidade da terra.

Antes de se analisar de forma mais pontuada as duas principais vertentes deste artigo - cultura cibernética e identidade --, torna-se importante uma breve revisão bibliográfica em relação às concepções de cultura em diversas áreas de conhecimento e também na concepção dos Estudos Culturais.

\section{CONCEPÇÕES DE CULTURA: BREVE EXCURSÃO CONCEITUAL}

Pensar no conceito de cultura é, na verdade, promover uma visita a diversas épocas e ideologias vivenciadas pelo ser humano, mesmo este sendo um conceito ilimitado e cambiante, revelando, muitas vezes, a fragmentação da identidade cultural. Em uma primeira análise, cultura, derivada da palavra latina colere, significava o ato de cultivar o solo, de promover a vida. Em outro contexto, cultura pôde ser vista como o conjunto inter-relacionado de crenças, costumes, formas de conhecimento, arte, que são adquiridos pelos indivíduos enquanto membros de uma sociedade particular e que podem ser estudados cientificamente, conforme assegurou Edward Tyler.

Partindo dessa análise, cultura corresponde às formas de organização de um povo, seus costumes e tradições transmitidos de geração para geração que, a partir de uma vivência e tradição comum, apresentam-se como a identidade desse povo. Em outros momentos, a cultura foi caracterizada como a metáfora da mistura, das manifestações híbridas. 
Em outra vertente sociológica, pode-se definir cultura como a soma das ideias, das práticas e dos objetos materiais compartilhados que as pessoas usam para se adaptar aos seus ambientes. Apesar de sua importância na vida humana, a cultura é frequentemente "invisível". Isto é, as pessoas tendem a considerar sua própria cultura como um dado, pois ela não parece ser tão "racional" e natural, sendo que raramente pensam sobre ela. No entanto, há um consenso sobre o fato de que cultura é aprendida, de que ela permite a adaptação humana ao ambiente natural, que ela é grandemente variável e que se manifesta em instituições, padrões de pensamento e objetos materiais (SANTAELLA, 2008).

Além disso, a partir das teorias de regulação e governamento de Foucault, é possível inferir que cultura realmente não é um dado natural, mas sim construída pelo discurso (THOMPSON, 2005). Ainda nessa perspectiva, percebemos que "a cultura é alimentada, criada, reproduzida, reforçada e, por vezes, subvertida, largamente, pelas narrativas com protagonistas pontuais, em circunstâncias e lugares datados (indiferentemente de sua veracidade)" (SILVEIRA, 2005, p. 199).

Durante séculos, viveu-se um etnocentrismo cultural, em que alguns povos julgavam a cultura do outro tendo apenas como ponto de partida as suas bases culturais. Assim, hierarquizavam-se essas culturas segundo alguns critérios, como a capacidade de produção material, criando uma falsa atmosfera de que havia culturas mais avançadas do que outras, visão esta que hoje, com a cultura digital, deve constituir-se em uma falácia.

Tendo como suporte a concepção antropológica, cultura é, em sua essência, plural e relativista, ou seja, o mundo está dividido em diferentes culturas, cada uma apresenta valor em si mesmas; para os humanistas, no entanto, algumas pessoas têm mais cultura do que outras e alguns produtos humanos - tais como a literatura, música, etc - são mais culturais do que outros. Assim, existiria o que se denomina de alta cultura e baixa cultura, além de cultura de massas ${ }^{2}$, entre outras designações comuns no século XX. Entretanto, esse conceito não se coaduna com a concepção de cultura para os Estudos Culturais, concepção que será utilizada neste artigo, pois os EC têm como propósito

\footnotetext{
${ }^{2}$ Apesar de mencionar a cultura de massas em alguns momentos, ela não será o enfoque principal deste trabalho.
} 
[...] compreender as metamorfoses da noção de cultura na última metade do século XX, questionar tanto os modos em que a cultura funciona na época da globalização como os riscos de uma visão da sociedade reduzida a um caleidoscópio de fluxos culturais que leve a esquecer que nossas sociedades também são regidas por relações econômicas, políticas [...] (MATTELARD, 2010, p. 17)

Boas (2004) pensava a cultura como uma alternativa pluralista e relativista contra o racismo científico e o evolucionismo cultural etnocêntrico, sendo então mais apropriado, para ele, o termo culturas. A concepção boasiana de cultura "tem como fundamento um relativismo de fundo metodológico, baseado no reconhecimento de que cada ser humano vê o mundo sob a perspectiva da cultura em que cresceu." (2004, p. 18). Assim, o antropólogo contestava o pensamento de cultura enquanto traço tomado como referência a tradição (que é hegemônica), pois a cultura seria um sistema, que não se esgota no traço que se pode descrever, enfatizando as particularidades das sociedades: uma visão de cultura como diversidade. Malinowski, que também compartilhava da visão de Boas, aceitou a existência de uma ciência da cultura, propondo uma teoria funcionalista da cultura que se aplicasse a ela. Sua teoria, conforme nos assegura Santaella (2008), considerava a cultura como um aparato instrumental dirigido para um fim.

Strauss, também contrário ao evolucionismo cultural, acreditava que os traços culturais de uma sociedade (mitos, rituais, práticas alimentares etc.) só podem ser compreendidos se analisados em conjunto. Para ele, a cultura está baseada em princípios universais, mas, por outro lado, também devem ser levados em consideração os detalhes que distinguem uma cultura da outra. Sob o impacto dessa perspectiva estruturalista, o antropólogo formulou sua própria maneira de compreender o homem: o que distingue o ser humano dos outros animais é o uso de símbolos para se comunicar, ideia também defendida por Thompson (2005), que enfatiza que se deve levar em conta que os contextos e os processos socialmente estruturados também são elementos a serem considerados ao se analisar questões relativas à cultura.

Para a autora, a cultura, pensada como um conjunto de crenças, de valores e de significados que o homem compartilha com seu grupo foi modificada pelo advento na sociedade das novas tecnologias, que fizeram com que os povos distantes e diferentes, sob muitos pontos de vista, passassem a dividir um imaginário comum. Essa similaridade de experiência e de imagens resultou em um processo de "pseudo 
homogeneização" cultural, e uma suposta interferência no caráter identitário de um povo.

A partir da emergência dos Estudos Culturais, a concepção de cultura transmutase de "um conceito impregnado de distinção, hierarquia e elitismo segregacionistas para um outro eixo de significados em que se abre um amplo leque de sentidos cambiantes e versáteis" (COSTA, 2005, p. 108). Ou seja: "Cultura deixa, gradativamente, de ser domínio exclusivo da erudição, da tradição literária e artística, de padrões estéticos elitizados, e passa a contemplar, também, o gosto das multidões” (Ibidem).

Dessa forma, "Os Estudos Culturais expressam, então, uma tentativa de 'descolonização' do conceito de cultura” (COSTA, 2005, p. 109), pois cultura passa a ser "expressão das formas pelas quais as sociedades dão sentido e organizam suas experiências comuns; cultura como o material de nossas vidas cotidianas, como a base de nossas compreensões mais corriqueiras" (Ibidem). O ciberespaço, na contemporaneidade, favorece a inscrição de outros grupos e sujeitos coletivos no mapa cultural, a partir dos descentramentos dos impérios culturais e da visibilidade de novos contornos da cultura, de culturas consideradas periféricas por diversas épocas.

\section{O CIBERESPAÇO E A "TRANSCULTURALIDADE”}

De acordo com Kenway (2001), o ciberespaço é um "lugar” sem cara de lugar e sem espaço, pois não há em seu interior fronteiras ou corpos, apenas textos e imagens e sons feitos de bits e bytes; um espaço transnacional, um "lugar" que não tem os aspectos de espaço, sem fronteiras, representando um lugar de peregrinação, de andarilho. Este espaço oferece novas relações entre produtores e consumidores de textos culturais, pois permitem aos sujeitos serem não apenas consumidores ativos ou passivos dos produtos de informação e da cultura global, mas agentes de seus próprios produtos culturais e também distribuidores desses elementos.

Com essa estrutura virtual, notam-se mudanças nas obras e produções da atualidade: as construções artísticas e literárias circulam nesse espaço de forma mais livres e, assim, encurtam as distâncias entre as linguagens erudita e popular. Parafraseando a ideia de Santiago (1998), diria que seria a ascensão da cultura e o declínio da arte. Ou seja, o ciberespaço possibilita um corte de hierarquias entre alta e 
baixa cultura, desfazendo, dessa forma, o que pode ser um viés para o preconceito acadêmico em relação à cultura popular.

Outro ponto a ser destacado em relação à cultura cibernética diz respeito à despersonalização das obras, característica da pós-modernidade, pois nessa esfera parece não se ter mais estilos ou visões particulares do mundo a se expressar e, sim, uma "transculturalidade", o que seria uma espécie de movimentação de algumas culturas, que se tornaram fluidas. Não se trata, no entanto, da passagem de um elemento para outro, mas de um imbricamento de uma cultura em outra, da união de diferentes princípios em um mesmo espaço social

No entanto, há diversos posicionamentos em relação à cultura digital. Para o filósofo Jameson, por exemplo, essa despersonalização pós-moderna é resultante do fato de que vivemos na era da paródia vazia, na qual nada de pessoal pode ser criado porque tudo já foi feito (RAMAL, 2002). Assim, ele acredita que o sujeito foi extinto da cultura. Seguindo esta mesma linha de pensamento, Lyotard afirma que o desenvolvimento das tecnologias se tornou um meio de intensificar a efemeridade das coisas, entre elas das manifestações culturais. Virilio acrescenta que a cibercultura traz consigo o fenômeno da "perda da orientação" (RAMAL, 2002, p. 69), além de a mídia ser um agente de extinção da cultura e o fim do sujeito.

Apesar de alguns autores (como já demonstrado anteriormente) terem uma visão pessimista em relação às tecnologias e às manifestações culturais oriundas dessas ferramentas, Pierre Lévy (1996) contraria essa perspectiva. Para ele, as TIC são uma tecnologia intelectual, que trazem consigo um novo modo de pensar o mundo e de conceber as relações com o conhecimento e com elementos culturais. Assim, pode-se inferir que não há um declínio da cultura, mas um novo modo de representar essas manifestações.

Em contrapartida, Escosteguy (2005) afirma que a constituição das diversas identidades culturais dos sujeitos, cada vez mais mediadas pelas tecnologias da comunicação, merece a atenção dos Estudos Culturais enquanto objeto de pesquisa justamente por possibilitar essa antropofagia ${ }^{3}$. É importante notar, entretanto, que esses

\footnotetext{
3 Refiro-me aqui ao movimento Antropofágico (1928) da literatura modernista, liderado por Oswald de Andrade, no entanto, resguardando as devidas proporções. No primeiro, o poeta não se opõe drasticamente à civilização industrializada, mas propõe cautela ao absorver aspectos culturais de outrem para que não haja sobreposição de culturas ou uma excessiva fragmentação. Em relação à
} 
fenômenos podem ser resultados dessa euforia cultural, como já ocorreu no passado em outras eras culturais. Mas, ao mesmo tempo, é necessário perceber que não há linearidade na passagem de uma era cultural para outra - exemplo da cultura impressa para a digital --, pois elas se sobrepõem, misturam-se, criando tecidos culturais híbridos e densos. E esses fios ficaram mais entrelaçados com a chegada da cultura digital.

\section{CULTURA ON-LINE E AS MÚLTIPLAS IDENTIDADES}

É sabido que as novas tecnologias, dentre elas o computador através da internet, constituem, a partir de vários aspectos, uma fonte alternativa de informações. Dessa forma, conforme nos assegura Pretto (2001), vivemos em uma sociedade do mass media, a sociedade da comunicação generalizada, que está introduzindo modificações profundas no conjunto de valores da humanidade, estabelecendo uma nova ordem e concepções da identidade dos sujeitos.

Pretto observa que com a assunção das máquinas, viveu-se um momento especial no mundo contemporâneo: a superação do homem pela máquina - da razão (da ciência e do progresso) pela imaginação e pelos meios de comunicação e informação. Essas transformações vão colocando a modernidade ${ }^{4}$ em seu limite histórico e aponta para uma mudança no modo de produção de novos modelos em um tempo em que o homem deixa de ser o centro, e a informação, produção e a circulação de imagens, através das novas tecnologias, passam a ser os vetores mais significativos, constituindo, dessa forma, uma realidade virtual.

Com a internet, tem-se a possibilidade de uma comunicação "muitos-a-muitos" e, além disso, as diferentes relações de produção e consumo dos produtos culturais, como abordado no item anterior, que veiculam nesse meio virtual, re-significando os estilos culturais. Dessa forma, esse meio fornece oportunidade para que pessoas representem a si próprias em suas próprias vozes, rompendo com a hegemonia cultural e apresentando suas identidades. Ou seja, aquelas pessoas que são vítimas do estereótipo e

cibercultura, penso ser necessário o imbricamento cultural, mas que elementos identitários de diversas culturas possam também ser mantidos

${ }^{4}$ É importante salientar que existe um embate filosófico significativo entre o declínio da modernidade e o desenvolvimento da pós-modernidade, o que não se torna objeto deste trabalho. Maiores detalhes sobre essa transição, torna-se importante a leitura de Jean-François Lyotard, Luicen Sfez, David Harvey, todos mencionados pelo último autor no livro "Condição Pós-moderna", que consta nas referências deste artigo. 
da marginalização têm a possibilidade, caso desejem, de reescrever suas identidades através da sua própria produção cultural.

Para se pensar em conceito de identidade, torna-se necessário, a priori, um revisitar de ideologias em relação ao homem, principalmente a partir das concepções de Foucault, quando este o define como um ser de linguagem e, dessa forma, estudá-lo seria, na verdade, um processo de decifração simbólica, tanto do dito, como do não-dito, quanto do que está nas entrelinhas. O sujeito passa a ter toda uma capacidade simbólica e não mais é visto como algo objetivo, desde a modernidade.

Nessa perspectiva, as formulações de narrativas, tendo como ênfase elementos da história e das relações subjetivas, são o mapa para se conhecer os processos identitários dos sujeitos e suas reformulações. Assim, o homem se apresenta como um ser que se caracteriza pela subjetividade e pela consciência de si próprio como um indivíduo, mesmo que, para isso, como é comum nas relações mediadas pelas máquinas, assuma o lugar de uma persona, ou seja, represente-se por outra identificação.

Para Hall (2009), a identificação é uma construção, um processo nunca terminado, sempre "em processo", como um senso de pertença coletiva, no qual os indivíduos encontram matrizes de ancoragem, de continuidade de si ao longo do tempo. Dessa forma, as identificações devem ser concebidas como processo ambíguo, instável e inconcluso do sujeito, pois elas nada mais são do que processos de reconhecimento e utilização de valores, artefatos e estilo de vida de forma efêmera, ritualizada e provisória.

A partir da diversidade de identificações, característica da cibercultura, é possível se pensar nas múltiplas identidades quando o sujeito encontra-se conectado à rede, porque "o sujeito previamente vivido como tendo uma identidade unificada e estável está se tornando fragmentado; composto não de uma, mas de várias identidades, algumas vezes contraditórias ou mal resolvidas" (HALL, 2006, p. 12). Assim, notamos que "as identidades são construções sociais e culturais negociadas, que não existem sujeitos acabados, mas subjetividades em processo de construção, no plano individual, ou afirmar, num plano coletivo [...]” (RAGO, 2005, p. 49).

Pode-se entender que o sujeito pós-moderno não apresenta uma identidade fixa, essencial e permanente. A identidade torna-se uma "celebração móvel" (HALL, 2006, p. 13); ela é formada e transformada ao decorrer do tempo e a depender do contato com 
os sistemas culturais que rodeiam os sujeitos. É um processo que implica o reconhecimento da alteridade: é na relação com o outro que há identificação do sujeito como não-outro (HALL, 2006; OLIVEIRA, 2006).

Então,

Entendemos a identidade como conjunto de elementos dinâmicos, múltiplos da realidade subjetiva e da realidade social, que são construídos na interação. Consideramos que a construção de identidades é constitutiva da realidade social das práticas discursivas, juntamente com outras construções, como a construção de relações sociais entre os falantes e a construção de sistemas de conhecimento e crenças. (KLEIMAN, 2006, p. 280-281)

Ribeiro (2007, p. 85) infere que com as tecnologias da comunicação e informação, principalmente a internet, a identidade de um povo deixa de ser algo unitário e cede lugar para um sujeito coletivo que, aos poucos, interfere nas subjetividades e identidades. "O sujeito é o elo de uma teia de relações, formando um ecossistema, no qual, sozinho, não é ninguém." Isto é: a identidade é formada e transformada a partir da vivência em rede, o que gera modificações nas trocas de produtos culturais e imbricamentos de culturas.

As transformações da cultura nos séculos XX-XXI tornam-se um ponto relevante a ser levado em conta para este estudo em relação à cultura on-line. Santalella (2008) nos chama a atenção para a dicotomia em relação à concepção cultural existente até meados do século XX: a cultura erudita, das elites, e a cultura popular, produzida pelas classes dominadas. $\mathrm{O}$ desenvolvimento dos recursos tecno-industriais minimizou esta divisão, pois a cultura de massa tende a dissolver essa polarização, anulando suas fronteiras.

A cultura das mídias ${ }^{5}$ inaugura uma nova visão e começa a possibilitar aos seus consumidores a escolha entre produtos simbólicos alternativos. Nesse tipo de cultura, alguns questionamentos tornam-se importantes para a sua construção: a primeira questão seria onde e quando a cultura é produzida? Por quem ela é produzida? Quais meios são empregados para a produção dos bens simbólicos, meios artesanais, industriais, eletrônicos, etc? E, por fim, para quem ela é produzida? No entanto, na

\footnotetext{
${ }^{5}$ O conceito de cultura de mídias, ignorado por alguns pensadores sobre a cultura, está sendo delimitado neste artigo a partir da concepção de Lúcia Santaella (2008).
} 
contemporaneidade, todas essas referências tendem a se misturar de forma híbrida e indissociável.

Na cultura digital, há uma dinâmica de aceleração do tráfego, das trocas e das misturas entre as múltiplas formas, estratos, tempos e espaços da cultura, o que, ao ver de Canclini (apud SANTAELLA, 2008), revela que todas as culturas, na atualidade, são fronteiriças, fluidas, desterritorializadas. $\mathrm{Na}$ pós-modernidade, evidenciam-se os hibridismos culturais, os descentramentos da identidade e, ao mesmo tempo, a heterogeneidade da cibercultura, que pode ser revelada a partir das comunidades virtuais.

\section{COMUNIDADES VIRTUAIS E HETEROGENEIDADE CULTURAL}

As comunidades virtuais são os tipos de ambientes comunicacionais na rede, que se constituem em formas culturais e socializadoras do ciberespaço. São constituídas em torno de interesses comuns, e pode-se desenvolver, nesses espaços, conceitos de identidade e comunicação diferentes do mundo real. Assim, existem múltiplos ciberespaços que produzem nossas múltiplas identidades e que possibilitam que as pessoas experimentem diferentes e novas identidades (e identificações), ou que possam ocultar a sua subjetividade, experimentando novos "eus". Essa multiplicidade de identidade, característica da fluidez pós-moderna, gera uma identidade líquida, que pode ter uma noção libertadora para aqueles cujas identidades têm se estabilizado em torno de uma persona marcada por estereótipos negativos e marginalizados.

Essas comunidades são um tipo de aldeia dentro da cultura dos computadores. Assim, elas designam as novas espécies de associações fluidas e flexíveis de pessoas, ligadas através de uma rede. Cada vez mais, o ciberespaço e as culturas que ele abriga, tanto através das comunidades virtuais quanto de outros espaços cibernéticos, vão adquirindo caracteres múltiplos.

Esses ciberespaços produzem os sujeitos culturais, que se transformam, na era digital, em um sujeito múltiplo, descentrado, que apresenta uma identidade instável. A Cultura digital transforma o modo como pensamos o sujeito, o que pode alterar a estrutura de sociedade, pois esta cultura promove a pessoa com uma identidade fluida, através de um processo contínuo de formação de múltiplas subjetividades, mas ao 
mesmo tempo um sujeito global, com sentimento de pertença a um espaço local. "Podemos ser outros e, socialmente, podemos criar novos mundos, novos imaginários e novas relações sociais" (RAGO, 2005, p. 49).

\section{CONSIDERAÇÕES FINAIS}

O mundo virtual apresenta reflexos de uma sociedade pós-moderna. Tem como principal característica o desprendimento do aqui e agora. Dessa forma, nessa era de informações on-line, manifestações culturais tornam-se transitórias e a cultura desterritorializada, presente por inteiro em cada uma de suas versões nos ciberespaços, conforme assegura Lévy (1996).

A virtualização reinventa uma cultura nômade, espaço de peregrinação, de andarilho, através de interações sociais onde as relações podem se configurar sem a hierarquização das culturas ou processos sociais. Dessa forma, percebe-se um efeito "Moebius", definição de Lévy, em que não se nota mais as dicotomias público e privado, autor e consumidor, etc.

O ciberespaço mistura, de forma híbrida, as noções de unidade, de identidade e de localização, miscigenando as culturas, tornando-se, portanto, uma ferramenta indispensável e uma faceta de todo e qualquer local de prática humana, ou seja, de manifestações culturais.

\section{REFERÊNCIAS}

BOAS, Franz. Antropologia Cultural. Rio de Janeiro: Jorge Zahar, 2004.

BRYM, Robert J. (et all). Sociologia, sua bússola para um novo mundo. São Paulo: Thompson, 2006.

COSTA, Marisa Vorraber. Estudos Culturais e Educação - um panorama. In: SILVEIRA, Rosa Maria Hessel (org). Cultura, Poder e Educação. Canoas: Ed. ULBRA, 2005. P.107 - 120.

ESCOSTEGUY, Ana Carolina D. A recepção dos Estudos Culturais na comunicação: a especificidade brasileira. In: SILVEIRA, Rosa Maria Hessel (org). Cultura, Poder e Educação. Canoas: Ed. ULBRA, 2005. P. 83 - 93. 
FOUCOULT, Michel. A palavra e as coisas. São Paulo: Martins Fontes, 1981.

HALL, Stuart. Quem precisa da identidade? In: SILVA, Tomaz Tadeu da (org.). Identidade e diferença. Petrópolis: Vozes, 2000. P. 103 -131.

DP\&A: 2006.

A identidade cultural na pós-modernidade. 11 ed. Rio de Janeiro:

HARVEY, David. Condição pós-moderna: uma pesquisa sobre as origens da mudança cultural. 6 ed. São Paulo: Loyola, 1996.

KLEIMAN, Ângela e VIEIRA, Josênia Antunes. O impacto identitário das novas tecnologias da informação e comunicação (internet). In: MAGALHÃES, Izabel; GRIGOLETTO, Marisa e CORACINI, Maria José (orgs). Práticas identitárias linguagem e discurso. São Carlos: Claraluz, 2006.

KENWAY, Jane. Educando cibercidadãos que sejam "ligados" e críticos. In: A escola no contexto da globalização. 5 ed. Rio de Janeiro: Vozes, 2001.

LÉVY, Pierre. O que é virtual?. São Paulo: Editora 34, 1996.

MATTELART, Armand e NEVEU, Érik. Introdução aos Estudos Culturais. São Paulo: Parábola Editorial, 2004.

OLIVEIRA, Maria Bernadete Fernandes de. Alteridade e construção de identidades pedagógicas: (re)visitando teorias dialógicas. In: MAGALHÃES, Izabel; GRIGOLETTO, Maria e CORACINI, Maria José (orgs). Práticas identitárias, linguagem e discurso. São Carlos: Clara Luz, 2006.

PRETTO, Nelson de Luca. Uma escola sem/com futuro. Educação e multimídia. 3 ed. Campinas: Papirus, 2001.

RAGO, Margareth. Rir das origens. In: SILVEIRA, Rosa Maria Hessel (org). Cultura, Poder e Educação. Canoas: Ed. ULBRA, 2005. P. 39 a 53.

RAMAL, Andrea Cecília. Educação na cibercultura: hipertextualidade, leitura, escrita e aprendizagem. São Paulo: Artmed, 2002.

RIBEIRO, Ana Elisa. Ler na tela - letramento e novos suportes de leitura e escrita. In: COSCARELLI, Carla Viana e RIBEIRO, Ana Elisa. Letramento digital: aspectos sociais e possibilidades pedagógicas. 2 ed. Belo Horizonte: Autêntica, 2007.

SANTAELLA, Lucia. Culturas e artes do pós-humano. Da cultura das mídias à cibercultura. 3 ed. São Paulo: Paulus, 2008. 
SANTIAGO, Silviano. Redemocratização do Brasil (1979-1981): cultura versus arte. In: O cosmopolitismo do pobre: crítica literária e crítica cultura. Belo Horizonte: Editora UFMG, 2004.

SILVA, Tadeu Tomaz da (RG). Alienígenas na sala de aula - uma introdução aos estudos culturais em educação. 2 ed. Rio de Janeiro: Vozes, 1995.

THOMPSON, John B. O conceito de cultura e Transmissão e comunicação de massa. In: . Ideologia e cultura moderna. Teoria social, crítica na era dos meios de comunicação de massa. Petrópolis: Vozes, 1995.

THOMPSON, Kenneth. Estudos Culturais e Educação no mundo contemporâneo. In: SILVEIRA, Rosa Maria Hessel (org). Cultura, Poder e Educação. Canoas: Ed. ULBRA, 2005. P.15 - 38 .

RECEBIDO EM: 01 de novembro de 2012

APROVADO EM: 06 de dezembro de 2012 